\title{
Regadenoson for myocardial perfusion imaging: Is it safe?
}

\author{
Fadi G. Hage, MD, FASH, FACC \\ a Division of Cardiovascular Disease, Department of Medicine, University of Alabama \\ at Birmingham, Birmingham, AL \\ b Section of Cardiology, Birmingham Veterans Affairs Medical Center, Birmingham, AL \\ ' Division of Cardiovascular Medicine, American University of Beirut Medical Center, \\ Beirut, Lebanon
}

Received May 21, 2014; accepted May 21, 2014

doi: $10.1007 /$ s $12350-014-9922-4$

\section{See related article, pp. 862-868}

\section{PRIMUM NON NOCERE (UNCERTAIN ORIGIN; OFTEN INCORRECTLY ATTRIBUTED TO THE HIPPOCRATIC OATH)}

Regadenoson is currently the most widely used pharmacologic stress agent for myocardial perfusion imaging (MPI) with millions of doses administered annually in the US. In November 2013, the US Food and Drug Administration (FDA) issued a Drug Safety Communication warning health care professionals of the rare but serious risk of heart attack and death with use of either regadenoson or adenosine. ${ }^{1}$ In this issue of the Journal, Rosenblatt et al report on 2 cases of asystole following regadenoson administration for MPI in stable outpatients. $^{2}$ These reports raise legitimate concerns with regard to safety of regadenoson considering its widespread use and the dictum of "do no harm."

\section{MYOCARDIAL INFARCTION}

In association with the Drug Safety Communication, the FDA approved changes to the drug label of regadenoson to warn of the possibility of myocardial infarction (MI), ventricular arrhythmias, and cardiac arrest. The FDA also advised physicians to avoid the use of regadenoson in

Reprint requests: Fadi G. Hage, MD, FASH, FACC, Division of Cardiovascular Disease, Department of Medicine, University of Alabama at Birmingham, Lyons Harrison Research Building 314, 1900 University BLVD, Birmingham, AL 35294; fadihage@uab.edu

J Nucl Cardiol 2014;21:871-6.

1071-3581/\$34.00

Copyright (C) 2014 American Society of Nuclear Cardiology. patients with symptoms or signs of acute myocardial ischemia, because these patients may be at greater risk of serious cardiovascular reactions to regadenoson. To date, there have been 2 published case reports of acute ST elevation MI occurring within minutes of regadenoson injection. ${ }^{3,4}$ A third case report describes chest pain in a patient with hypertrophic cardiomyopathy following infusion of regadenoson; this patient had a reversible perfusion defect on imaging and normal coronary arteries on angiography, and symptoms were attributed to presumed vasospasm. ${ }^{5}$ In addition, the FDA analyzed its Adverse Event Reporting System (FAERS) database and reported 26 MIs and 29 deaths after regadenoson administration during the period extending from June 24, 2008, to April 10, 2013 and $6 \mathrm{MIs}$ and 27 deaths after adenosine administration from May 18, 1995, to April 10, 2013. The majority, although not all, of these events occurred within 6 hours of drug administration. The FDA points out that some of these deaths occurred when the drugs were administered with exercise stress, which is not an FDAapproved use of these drugs. Because these cases were spontaneously reported, little information is available regarding the circumstances of the events.

The adenoscan vs regadenoson comparative evaluation for myocardial perfusion imaging (ADVANCEMPI) trials, two multi-center, double-blind, phase 3 studies, established the non-inferiority of regadenoson compared to adenosine for the detection of reversible perfusion defects. ${ }^{6,7}$ These trials randomized a total of 2,015 patients to sequential (median of 7 days between scans) adenosine-regadenoson MPIs vs adenosineadenosine MPIs in a 2:1 ratio. The studies reported no serious adverse events, including death or MIs, in either group. A small open-label, dose-escalation study of regadenoson (10-500 $\mu \mathrm{g}$ intravenous bolus) performed in 38 subjects to characterize the dose dependence of regadenoson-induced coronary hyperemia, reported 1 
moderate adverse event (hypotension) and one serious adverse event (MI). ${ }^{8}$ The MI occurred 2 days after drug administration and was considered unrelated to the exposure to regadenoson. ${ }^{8}$

Since the approval of regadenoson, multiple prospective studies have reported safety data for regadenoson alone and in combination with exercise and have examined its safety in special populations such as patients with kidney disease and pulmonary disease. ${ }^{9-16}$ These studies combined had data on $\sim 2,300$ patients that received regadenoson and reported no deaths or MIs. In an on-going multi-center phase $3 \mathrm{~b}$ study examining the administration of regadenoson following inadequate exercise stress test compared to regadenoson alone (ClinicalTrials.gov identifier NCT 01618669) that has enrolled more than 1,000 patients, one patient had an acute coronary syndrome following regadenoson administration. This patient started to experience ischemic symptoms while exercising prior to receiving regadenoson. The subject recovered (personal communication with Astellas). Brinkert et al recently reported prospective safety data of regadenoson administration to 1,764 consecutive patients $(90 \%$ in combination with submaximal exercise) at a single institution. In this study, there were 8 adverse events $(0.5 \%)$ but no deaths, MIs, or hospital admission following stress MPI. ${ }^{17}$

The mechanism for the possible association between regadenoson administration and acute $\mathrm{MI}$ is not clear. Similar associations have been reported with adenosine and dipyridamole. ${ }^{1,4}$ Possible mechanisms include coronary artery steal, hypotension due to peripheral vasodilation, and coronary artery spasm.

\section{ASYSTOLE}

Adenosine causes coronary vasodilation by activating the $\mathrm{A} 2 \mathrm{~A}$ receptor and undesirable side-effects through its activation of $\mathrm{A} 1, \mathrm{~A} 2 \mathrm{~B}$, or $\mathrm{A} 3$ adenosine receptors. ${ }^{18}$ Specifically, activation of A1 receptors in the sinoatrial and atrioventricular (AV) nodes and in atrial and ventricular myocytes is known to have negative chronotropic and dromotropic effects. In contrast to adenosine, regadenoson is a selective agonist of the $\mathrm{A} 2 \mathrm{~A}$ receptor and has a 13 -fold greater affinity for A2A than for A1 and very low affinity for A2B and A3 receptors. ${ }^{19}$ In guinea pig isolated hearts, the potency of regadenoson to increase coronary blood flow is much higher than to slow AV conduction (Figure 1, CV Therapeutics, unpublished data, courtesy of L. Belardinelli). Thus, the functional selectivity of regadenoson for A2A-mediated coronary vasodilation relative to A1mediated AV nodal conduction slowing is $>200$-fold. Despite its high selectivity for A2A, regadenoson has a relatively low affinity for this receptor. However, activation of a small fraction of coronary A2A receptors is sufficient to cause near-maximal vasodilation. ${ }^{20}$ In guinea pig isolated hearts, occupancy by regadenoson of $4 \%$ and $25 \%$ of A2A receptors is sufficient to cause $50 \%$ and $90 \%$ of maximal coronary conductance, respectively. Due to this low affinity, regadenoson binding is readily reversible, the onset of its action is rapid, and the duration of action is brief.

These pharmacological characteristics are consistent with the lower incidences of first- $(2.8 \%$ vs $7.0 \%)$ and second-degree $(0.1 \%$ vs $1.5 \%) \mathrm{AV}$ block compared to adenosine in the ADVANCE-MPI clinical trials. ${ }^{6,7}$ The ADVANCE-MPI trials and the other prospective clinical trials reported no cases of asystole and a single case of complete AV block in a subject with asthma that recovered. ${ }^{9}$ Since then a case report of asymptomatic complete AV block which occurred after regadenoson administration and immediately reversed with aminophylline has been published. ${ }^{21}$ Another case was reported of a patient who developed high-grade AV block after administration of regadenoson followed by asystole. ${ }^{22}$ Chest compressions were initiated and aminophylline given. The patient regained a palpable pulse and consciousness after approximately $1 \mathrm{~min}$. Several other cases of AV block have been reported to FAERS. In this issue of the Journal, Rosenblatt et al $^{2}$ report on 2 cases of asystole in stable outpatients that led to hemodynamic collapse in the absence of baseline conduction abnormalities or interfering medications. In the study by Brinkert et al of 1,764 patients, 7 patients experienced vasovagal episodes (symptomatic hypotension with inappropriate bradycardia or failure of compensatory tachycardia) of which 2 progressed to asystole lasting 10-30 seconds. Finally, we have observed 2 cases of asystole following regadenoson administration at the University of Alabama at Birmingham-UAB (personal observations, unpublished). Both cases resolved spontaneously after few seconds without administration of aminophylline or other medications.

Regadenoson, via activation of the $\mathrm{A} 2 \mathrm{~A}$ receptors, can cause peripheral vasodilation (although less so than coronary vasodilation) that may lead to a drop in blood pressure. Accordingly, in the ADVANCE-MPI trials, a systolic blood pressure drop $>35 \mathrm{~mm} \mathrm{Hg}$ occurred in $7 \%$ of patients. Activation of peripheral A2A causes increased release of adrenergic neurotransmitters, ${ }^{23}$ whereas activation of nucleus tractus solitarii A2A is reported to inhibit regional sympathetic and hemodynamic reflex responses. ${ }^{24}$ In laboratory animals and in humans, regadenoson decreases systolic and diastolic blood pressures and causes an increase in heart rate. ${ }^{8,23,25,26}$ Thus, the drop in blood pressure is usually countered by direct sympathoexcitation and an autonomically mediated elevation in heart rate that increases cardiac output and maintains adequate perfusion of vital organs. Consistent with this, the prevalence of adverse 


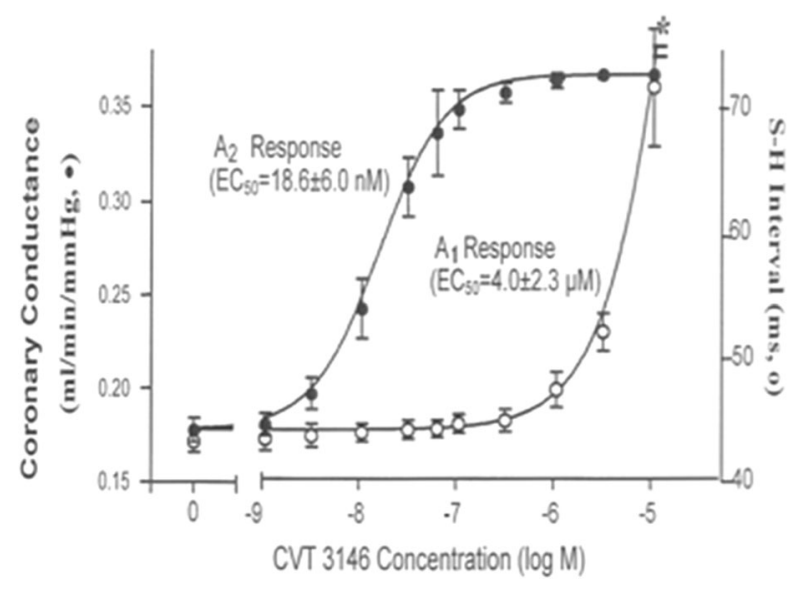

Figure 1. The relationship between the concentration of regadenoson (CVT 3146) and coronary conductance on the left and stimulus-to-His bundle interval $(\mathrm{S}-\mathrm{H})$ on the right in isolated guinea pig hearts. Note that the half-maximum effective concentration (EC50) for coronary conductance is on a lower order of magnitude (nM compared to $\mu \mathrm{M})$.

events during administration of regadenoson in healthy volunteers was greater in standing than in supine subjects. $^{27}$ Therefore, in the presence of autonomic dysfunction that attenuates a reflex increase of heart rate to maintain blood pressure and/or diminished sympathoexcitation, the A2A-mediated effect of regadenoson to reduce peripheral resistance may lead to a greater normal drop in blood pressure and cardiac output. In dogs and rats treated with hexamethonium, a blocker of impulse transmission through autonomic nerve ganglia, regadenoson administration $(5 \mu \mathrm{g} / \mathrm{kg})$ did not increase heart rate, and the drop in blood pressure was much greater than in untreated control animals. ${ }^{23,28}$ It is therefore possible that patients with poor autonomic control of cardiovascular function may experience an acute drop in blood pressure leading to hemodynamic collapse upon administration of regadenoson, especially when in the standing posture, such as when administered in association with exercise.

Another possible mechanism for hemodynamic deterioration may be endogenous adenosine generation. Myocardial ischemia may ensue after regadenoson administration due to the sudden drop of systemic blood pressure or alternatively, from coronary steal in patients with severe coronary obstruction and/or the presence of collaterals. Ischemia results in myocardial adenine nucleotide breakdown and increased adenosine formation. Adenosine slows heart rate and AV conduction via A1 receptor activation. Patients predisposed to conduction block and/or ischemia in either the sinoatrial or AV nodes would be expected to have higher sensitivity to the A1 receptor-mediated conduction slowing caused by endogenously released adenosine or exogenous regadenoson. This predisposition may depend on factors such as fibrosis in the node(s) and surrounding tissues, which reduces baseline electric conduction, the anatomy of the arteries supplying the sinoatrial and AV nodes, the presence of anatomy that is favorable to coronary steal, and patient variability in levels of plasma adenosine and A2A receptor expression. ${ }^{29-33}$

\section{DRUG SAFETY}

To assess the risk of regadenoson, or any other medicine, one has to examine the totality of evidence from clinical trials as well as post-marketing surveillance. In the pivotal clinical trials, no cases of MI, death, or asystole were seen with regadenoson. Although clinical trials usually identify common adverse events, assessment of infrequent but serious events based on clinical trials alone is problematic, because these trials recruit only few thousand patients, select patients who are healthier than what is ultimately seen in practice and are powered for efficacy but underpowered for risk. Several cases of MI, complete AV block, and asystole have been seen in post-marketing clinical trials that have examined higher risk populations and/or used protocols which may be associated with higher risk (i.e., regadenoson with exercise) and in case reports and postmarketing surveillance. Although data derived from the later source overcome some of the limitations discussed above with regard to the number of subjects and the presence of comorbidities, it has its own limitations.

First, the data are incomplete. For example, it is not possible from the limited data to determine whether the reported cases of MIs and death with regadenoson are causally related to the drug. Second, it is hard to estimate the level of risk relative to benefit. To assess risk, both the numerator and the denominator need to be accurately measured. A recent survey by ASNC indicated that regadenoson is by far the most used pharmaceutical stress agent (83\% in 2013 with $7 \%$ increase compared to 2012). ${ }^{34}$ It is estimated that 2-3 million regadenoson MPIs are currently performed per year in the US. Nevertheless, the reported cases are voluntary and may represent a fraction of the total number of adverse events, because some cases may not be reported (for example, the 2 cases of asystole mentioned earlier at UAB). For these reasons, the FDA announced in December 2013 that it is considering the use of electronic medical records to directly assess drugs in the post-market setting and help it determine risk factors associated with the development of adverse events. $^{35}$ Hopefully, this will help the agency in the future have direct access to de-identified records of drug-induced adverse events and enhance the assessment of risk and safety. 


\section{Rest}

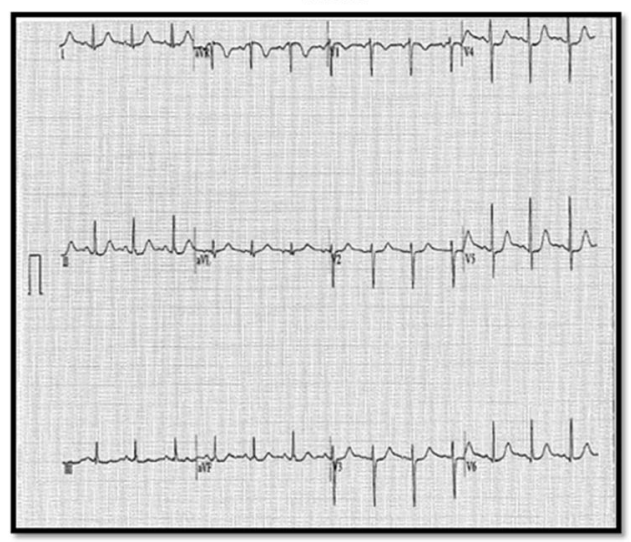

Dobutamine

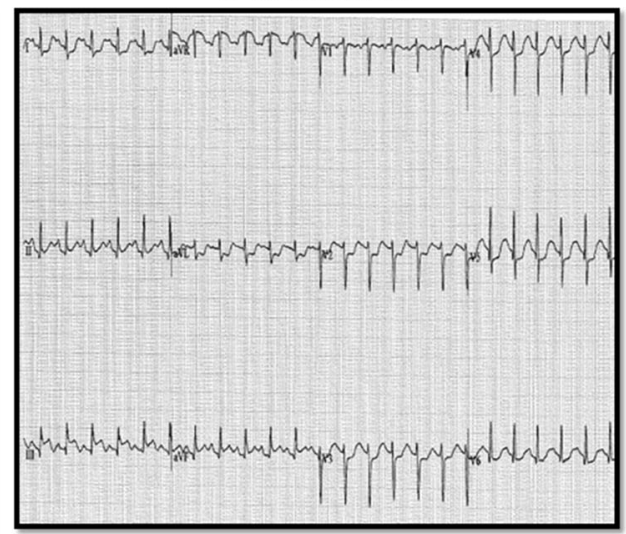

Figure 2. Rest and dobutamine stress ECG of a 62-year old woman with severe chronic obstructive pulmonary disease on home oxygen, diabetes, hypertension, dyslipidemia, and history of MI in the past who presented to our institution with atypical chest pain and active wheezing. She developed inferior ST elevation with reciprocal depression in anterolateral leads during dobutamine infusion. The patient was emergently transferred to the catheterization laboratory where angiography showed complete occlusion of proximal right coronary artery (which fills distally via left-sided collaterals) and underwent successful stenting.

Beyond the accurate assessment of risk, we need to consider whether this risk is confounded by indication. In this regards, regadenoson MPI is administered to patients with known or suspected coronary artery disease who are at risk of developing adverse events, whether or not they receive regadenoson. Further, we need to consider the alternatives if regadenoson MPI is not performed. There are no data currently comparing the risk of regadenoson to other stress agents, but previous studies have shown a risk of MI, death, and serious arrhythmias with adenosine, dipyridamole, dobutamine, and exercise ${ }^{36-39}$ (Figure 2). Performing such comparisons is needed but will require very large databases and will be limited by comparisons across different eras, because, as mentioned earlier, a majority of pharmaceutical stress tests are currently performed with regadenoson. Also, it is not clear how to differentiate an MI from stress-induced ischemia in this setting. For example, in the case presented in Figure 2, did the patient have an ST-elevation MI or ST-elevation secondary to dobutamine-induced ischemia (collateraldependent steal) indicating a positive test? Biomarkers are not particularly helpful to differentiate the two in this setting, because the rise in biomarkers is dependent on the timing of restoration of blood flow (if it is an MI) and on the procedure itself (percutaneous coronary intervention) which may induce a rise of biomarkers even if the ST elevation was originally caused by dobutamine-induced ischemia.

In conclusion, cases of MI, serious arrhythmias including complete AV block and asystole, and even death have been reported with regadenoson MPI.
"Cardiac resuscitation equipment and trained staff should be available before administering Lexiscan or Adenoscan" and these drugs should be avoided "in patients with symptoms or signs of acute myocardial ischemia such as unstable angina or cardiovascular instability" as indeed should any form of stress testing, including exercise. According to the available limited data, the absolute risk appears to be small and may not be different from other stress agents. Further data comparing safety of regadenoson to other stress agents are urgently needed. Finally, our assessment of risk should be weighed against the benefit of any intervention such that we "first do no net harm," as recently suggested. ${ }^{40}$

\section{Acknowledgments}

I thank Drs Luiz Belardinelli and John Shryock for providing information on the pharmacology of regadenoson and editorial comments for this review. Dr Belardinelli is an employee of Gilead Sciences, Inc. and co-inventor of regadenoson. Dr Shryock is a former employee of Gilead Sciences, Inc.

\section{Disclosures}

Dr Hage has received research grants and serves on a Scientific Advisory Board for Astellas Pharma USA.

\section{References}

1. http://www.fda.gov/drugs/drugsafety/ucm375654.htm. Accessed April 30, 2014 
2. Rosenblatt J, Mooney D, Dunn T, Cohen M. Asystole following regadenoson infusion in stable outpatients. J Nucl Cardiol 2014;In same issue of this editorial.

3. Hsi DH, Marreddy R, Moshiyakhov M, Luft U. Regadenoson induced acute ST-segment elevation myocardial infarction and multivessel coronary thrombosis. J Nucl Cardiol 2013;20:481-4.

4. Shah S, Parra D, Rosenstein RS. Acute myocardial infarction during regadenoson myocardial perfusion imaging. Pharmacotherapy 2013;33:e90-5.

5. Bagley SJ, Lilly SM, Litwack AJ. Coronary vasospasm during a regadenoson stress test. Cardiol J 2012;19:92-4.

6. Iskandrian AE, Bateman TM, Belardinelli L, Blackburn B, Cerqueira MD, Hendel RC, et al. Adenosine versus regadenoson comparative evaluation in myocardial perfusion imaging: Results of the ADVANCE phase 3 multicenter international trial. J Nucl Cardiol 2007;14:645-58.

7. Cerqueira MD, Nguyen P, Staehr P, Underwood SR, Iskandrian AE. Effects of age, gender, obesity, and diabetes on the efficacy and safety of the selective A2A agonist regadenoson versus adenosine in myocardial perfusion imaging: Integrated ADVANCE-MPI trial results. J Am Coll Cardiol Cardiol Image 2008;1:307-16.

8. Lieu HD, Shryock JC, von Mering GO, Gordi T, Blackburn B, Olmsted AW, et al. Regadenoson, a selective A2A adenosine receptor agonist, causes dose-dependent increases in coronary blood flow velocity in humans. J Nucl Cardiol 2007;14:514-20.

9. Ananthasubramaniam K, Weiss R, McNutt B, Klauke B, Feaheny $\mathrm{K}$, Bukofzer S. A randomized, double-blind, placebo-controlled study of the safety and tolerance of regadenoson in subjects with stage 3 or 4 chronic kidney disease. J Nucl Cardiol 2012;19:319-29.

10. Doukky R, Morales Demori R, Jain S, Kiriakos R, Mwansa V, Calvin JE. Attenuation of the side effect profile of regadenoson: a randomized double-blinded placebo-controlled study with aminophylline in patients undergoing myocardial perfusion imaging. “The ASSUAGE trial”. J Nucl Cardiol 2012;19:448-57.

11. Partington SL, Lanka V, Hainer J, Blankstein R, Skali H, Forman DE, et al. Safety and feasibility of regadenoson use for suboptimal heart rate response during symptom-limited standard Bruce exercise stress test. J Nucl Cardiol 2012;19:970-8.

12. Prenner BM, Bukofzer S, Behm S, Feaheny K, McNutt BE. A randomized, double-blind, placebo-controlled study assessing the safety and tolerability of regadenoson in subjects with asthma or chronic obstructive pulmonary disease. J Nucl Cardiol 2012;19: 681-92.

13. Parker MW, Morales DC, Slim HB, Ahlberg AW, Katten DM, Cyr $\mathrm{G}$, et al. A strategy of symptom-limited exercise with regadenoson-as-needed for stress myocardial perfusion imaging: a randomized controlled trial. J Nucl Cardiol 2013;20:185-96.

14. Ross MI, Wu E, Wilkins JT, Gupta D, Shen S, Aulwes D, et al. Safety and feasibility of adjunctive regadenoson injection at peak exercise during exercise myocardial perfusion imaging: The Both Exercise and Regadenoson Stress Test (BERST) trial. J Nucl Cardiol 2013;20:197-204.

15. Doukky R, Rangel MO, Wassouf M, Dick R, Alqaid A, Morales Demori R. The safety and tolerability of regadenoson in patients with end-stage renal disease: the first prospective evaluation. J Nucl Cardiol 2013;20:205-13.

16. AlJaroudi WA, Alraies MC, Cerquiera MD, Jaber WA. Safety and tolerability of regadenoson in 514 SPECT MPI patients with and without coronary artery disease and submaximal exercise heart rate response. Eur J Nucl Med Mol Imaging 2013;40:341-8.

17. Brinkert M, Reyes E, Walker S, Latus K, Maenhout A, Mizumoto $\mathrm{R}$, et al. Regadenoson in Europe: First-year experience of regadenoson stress combined with submaximal exercise in patients undergoing myocardial perfusion scintigraphy. Eur J Nucl Med Mol Imaging 2014;41:511-21.

18. Zoghbi GJ, Iskandrian AE. Selective adenosine agonists and myocardial perfusion imaging. J Nucl Cardiol 2012;19:126-41.

19. Gao Z, Li Z, Baker SP, Lasley RD, Meyer S, Elzein E, et al. Novel short-acting A2A adenosine receptor agonists for coronary vasodilation: Inverse relationship between affinity and duration of action of A2A agonists. J Pharmacol Exp Ther 2001;298:209-18.

20. Shryock JC, Snowdy S, Baraldi PG, Cacciari B, Spalluto G, Monopoli A, et al. A2A-adenosine receptor reserve for coronary vasodilation. Circulation 1998;98:711-8.

21. Pandit A, Unzek Freiman S. Complete heart block associated with regadenoson: A real side effect. J Nucl Cardiol 2012;19:1236-9.

22. Grady EC, Barron JT, Wagner RH. Development of asystole requiring cardiac resuscitation after the administration of regadenoson in a patient with pulmonary fibrosis receiving nacetylcysteine. J Nucl Cardiol 2011;18:521-5.

23. Dhalla AK, Wong MY, Wang WQ, Biaggioni I, Belardinelli L. Tachycardia caused by A2A adenosine receptor agonists is mediated by direct sympathoexcitation in awake rats. J Pharmacol Exp Ther 2006;316:695-702.

24. Minic Z, O'Leary DS, Scislo TJ. Nucleus tractus solitarii A(2a) adenosine receptors inhibit cardiopulmonary chemoreflex control of sympathetic outputs. Auton Neurosci 2014;180:32-42.

25. Hage FG, Heo J, Franks B, Belardinelli L, Blackburn B, Wang W, et al. Differences in heart rate response to adenosine and regadenoson in patients with and without diabetes mellitus. Am Heart $\mathbf{J}$ 2009;157:771-6.

26. Hage FG, Dean P, Iqbal F, Heo J, Iskandrian AE. A blunted heart rate response to regadenoson is an independent prognostic indicator in patients undergoing myocardial perfusion imaging. J Nucl Cardiol 2011;18:1086-94.

27. Gordi T, Frohna P, Sun HL, Wolff A, Belardinelli L, Lieu H. A population pharmacokinetic/pharmacodynamic analysis of regadenoson, an adenosine A2A-receptor agonist, in healthy male volunteers. Clin Pharmacokinet 2006;45:1201-12.

28. Zhao G, Serpllion S, Shryock J, Messina E, Xu X, Ochoa M, et al. Regadenoson, a novel pharmacologic stress agent for use in myocardial perfusion imaging, does not have a direct effect on the QT interval in conscious dogs. J Cardiovasc Pharmacol 2008;52:467-73.

29. Yesil M, Arikan E, Postaci N, Bayata S, Yilmaz R. Locations of coronary artery lesions in patients with severe conduction disturbance. Int Heart J 2008;49:525-31.

30. Abuin G, Nieponice A, Barcelo A, Rojas-Granados A, Leu PH, Arteaga-Martinez M. Anatomical reasons for the discrepancies in atrioventricular block after inferior myocardial infarction with and without right ventricular involvement. Tex Heart Inst J 2009;36:8-11.

31. Saadjian AY, Gerolami V, Giorgi R, Mercier L, Berge-Lefranc JL, Paganelli $\mathrm{F}$, et al. Head-up tilt induced syncope and adenosine A2A receptor gene polymorphism. Eur Heart J 2009;30:1510-5.

32. Hurle A, Sanchez-Quintana D, Ho SY, Bernabeu E, Murillo M, Climent V. Capillary supply to the sinus node in subjects with long-term atrial fibrillation. Ann Thorac Surg 2010;89:38-43.

33. Andreassi MG, Laghi Pasini F, Picano E, Capecchi PL, Pompella G, Foffa I, et al. Adenosine A2(A) receptor gene polymorphism $(1976 \mathrm{C}>\mathrm{T})$ affects coronary flow reserve response during vasodilator stress testing in patients with non ischemic-dilated cardiomyopathy. Pharmacogenet Genomics 2011;21:469-75.

34. 2013 Nuclear Cardiology Trend Survey. J Nucl Cardiol 2014; 21:Supplement 1.

35. https://www.fbo.gov/index? $\mathrm{s}=$ opportunity \& mode $=$ form $\& \mathrm{id}=\mathrm{a} 549$ $39566 \mathrm{ff} 0 \mathrm{f} 502 \mathrm{~b} 8 \mathrm{da} 95 \mathrm{ab} 23 \mathrm{e} 34 \mathrm{~d} 2 \mathrm{~b} \& \mathrm{tab}=$ core $\&$ tabmode $=l i s t \&=$. Accessed 05/02/2014. 
36. Stuart RJ Jr, Ellestad MH. National survey of exercise stress testing facilities. Chest 1980;77:94-7.

37. Cerqueira MD, Verani MS, Schwaiger M, Heo J, Iskandrian AS. Safety profile of adenosine stress perfusion imaging: results from the Adenoscan Multicenter Trial Registry. J Am Coll Cardiol 1994;23:384-9.

38. Lette J, Tatum JL, Fraser S, Miller DD, Waters DD, Heller G, et al. Safety of dipyridamole testing in 73,806 patients: The Multicenter Dipyridamole Safety Study. J Nucl Cardiol 1995;2:3-17.
39. Geleijnse ML, Fioretti PM, Roelandt JR. Methodology, feasibility, safety and diagnostic accuracy of dobutamine stress echocardiography. J Am Coll Cardiol 1997;30:595-606.

40. Sokol DK. "First do no harm" revisited. BMJ 2013;347:f6426. 